\title{
Brain Melanocortin Receptors are Involved In CRH-Mediated HPA Axis Activity And Thermogenesis
}

\author{
Koert de Vries ${ }^{\mathrm{a}}$, Csaba Nyakas ${ }^{\mathrm{b}, \mathrm{e}}$ Brian P. den Hartog ${ }^{\mathrm{a}}$, Bauke Buwalda ${ }^{\mathrm{c}}$, Anton J.W. Scheurink ${ }^{\mathrm{a}}$,

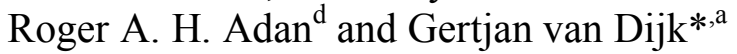

\begin{abstract}
Center for Behavior and Neurosciences, Departments of ${ }^{a}$ Neuroendocrinology, ${ }^{b}$ Molecular Neurobiology, and ${ }^{c}$ Behavioral Physiology, University of Groningen, The Netherlands; ${ }^{d}$ Rudolf Magnus Institute for Neurosciences, Department of Neurosience and Pharmacology, University Medical Center Utrecht, Utrecht, The Netherlands; ${ }^{e}$ Brain Physiology Research Group of Semmelweis University and Hungarian Academy of Sciences, Budapest, Hungary
\end{abstract}

\begin{abstract}
Recent studies indicate that corticotropin-releasing hormone (CRH) acts down-stream from brain melanocortin receptors (MC-Rs), however, much older evidence actually suggested the opposite. To reconcile this, rats were chronically infused centrally with the MC-R antagonist SHU9119 (0.5 nmol/day) over 14 days. Acute central CRH administration $(0.5 \mu \mathrm{g})$ caused temporal anorexia, which was not impaired by SHU9119 treatment relative to controls. SHU9119 treatment, however, did attenuate CRH-induced plasma ACTH and thermogenic responses. Since SHU9119 pair-fed rats showed generally similar effects as SHU9119-treated ad libitum feeding rats, the modulation of ACTH and thermogenic responses are not secondary to increased body weight by SHU9119 treatment. Central pre-treatment with the glucocorticoid receptor agonist dexamethasone $(10 \mu \mathrm{g})$ before CRH demonstrated that the inhibitory effect of SHU9119 treatment on the CRH-induced ACTH response was not attributed to increased glucocorticoid feedback. Peripheral dexamethasone pre-treatment $(25 \mu \mathrm{g} / \mathrm{kg}$ rat), on the other hand, more potently suppressed CRH-induced corticosterone responses in SHU9119-treated rats. This effect is explained by sensitization of the adrenal cortex to glucocorticoid feedback as a result of SHU9119 treatment. We conclude that MC-Rs act down-stream from CRH to facilitate CRH-induced HPA axis activation and thermogenesis, but not down-stream from CRH to facilitate anorexia.
\end{abstract}

Keywords: Melanocortins, Obesity, Central nervous system, HPA-axis, CRH, GR

\section{INTRODUCTION}

Corticotropin-releasing hormone $(\mathrm{CRH})$ is an important regulatory component in the central nervous control of energy fluxes in the body $[1,2]$. Within the hypothalamus, $\mathrm{CRH}$ is predominantly expressed in neuronal cell bodies located in the parvocellular division of the paraventricular hypothalamus (PVN). Among others, these neurons project to the median eminence (ME) where they secrete CRH into the hypophyseal portal circulation, from where $\mathrm{CRH}$ controls the release of adrenocorticotropic hormone (ACTH) from the anterior pituitary into the general circulation. In turn, this stimulates the secretion of glucocorticoids from the adrenal cortex [3]. The main glucocorticoid corticosterone (in rodents) or cortisol (in man) serves many functions in peripheral fuel metabolism and endocrine activity of numerous organs [4]. In addition to being involved in pituitary hormone secretion, a portion of these CRH neurons have been proposed to project to hindbrain and brain stem structures, which control autonomic outflow to the cardiovascular system and several organs involved in fuel homeostasis $[5,6]$. Finally, $\mathrm{CRH}$ is known to have acute [7] as well as prolonged anorexigenic effects [8], and promotes body weight loss $[8,9]$.

*Address correspondence to this author at the Nijenborgh 7, 9747AG Groningen, The Netherlands; Tel: +31 50 3632116; Fax: +31 50 3632331; E-mail: gertjan.van.dijk@rug.nl
Consistent with a role for $\mathrm{CRH}$ in the regulation of energy fluxes in the body are reports suggesting that this neuropeptide is implicated in the signaling cascade in the hypothalamus of leptin [10]. Administration of leptin into the third cerebral ventricle $(\mathrm{i} 3 \mathrm{cv})$ upregulates the expression of $\mathrm{CRH}$ in this region [10], and stimulates labeling of c-Fos (i.e., a marker of neuronal activity) in CRH-containing neuronal cell bodies in the PVN [11]. Furthermore, i3cv administration of the CRH antagonist $\alpha$-helical CRH over several days in mice prevents the effects of leptin on food intake and thermogenesis [12]. Besides CRH, also the brain melanocortin (MC) system is an important target of leptin in the CNS. For example, blockade of brain MC-Rs by i3cv administration of the MC-R antagonist SHU9119 prevents leptin's anorexigenic efficacy [13]. Because SHU9119 treatment also markedly attenuated c-Fos labeling in PVN neurons, it was previously hypothesized that the brain MC system acts as an intermediairy system linking leptin signaling to increased activation of $\mathrm{CRH}$ neurons. Consistent with this idea is the observation that $\mathrm{i} 3 \mathrm{cv}$ infusion of the MC- $\mathrm{R}$ agonist, melanotan-II (MTII), causes reductions in food intake that can be blocked by co-administration of the CRHreceptor antagonist, astressin [14]. The fact that CRHinduced anorexia could not be blocked by co-administration of the MC-R antagonist HS014, suggests that MC-Rs only act upstream from CRH neurons [15]. By other measures, however, data in literature suggest that the MC system is acting down-stream from $\mathrm{CRH}$ neurons. For example, cen- 
tral administration of immunoglobulins raised against endogenous MC-R ligands markedly reduced the thermogenic and metabolic responses to centrally administerd $\mathrm{CRH}$ in rats [16]. Furthermore, the data by Von Frijtag et al., [17] showed that central administration of SHU9119 in rats is able to blunt the ACTH response to foot shock stress. This could be explained by location of MC-Rs down-stream from $\mathrm{CRH}$ neurons. In order to reconcile the role of the MC system in CRH effects, we aimed to investigate further effects of $\mathrm{CRH}$ on ingestive behavior, HPA axis activity (including glucocorticoid feed-back), thermogenesis, and non-ingestive behaviors in rats that were chronically i3cv infused with SHU9119 or saline. Because chronic SHU9119 treatment causes obesity, we also included a group of rats that were i3cv infused with SHU9119, but were pair-fed to the salinetreated rats.

\section{METHODS}

\section{Animal Preparation}

Adult male Wistar rats, obtained from the breeding colony maintained by the Center for Behavior and Neurosciences at the University of Groningen and weighing between 400 and $450 \mathrm{~g}$ were used for the experiments. They were housed individually in Plexiglas cages $(25 \times 25 \times 30 \mathrm{~cm})$ on a layer of sawdust, in climate chambers under controlled temperature $\left(22 \pm 2{ }^{\circ} \mathrm{C}\right)$, relative humidity $(55-5 \%)$ and maintained on a 12:12-h light-dark cycle (lights off 15:00-03:00 hour). Animals were handled daily to minimize stress during experiments and weighed every day. The animals had ad libitum access to food (Hope Farms - Rat Mouse Hamster) and water except where noted. All methods and experiments were approved by the Animal Care Committee of the University of Groningen. Under isoflurane $/ \mathrm{N}_{2} \mathrm{O}$ anesthesia, rats were implanted stereotaxically with a 22-gauge stainlesssteel guide cannula (Plastic One, Roanoke, VA, USA) into the third cerebral ventricle and one positioned into the left lateral cerebral ventricleaccording to Paxinos and Watson [18]. All other techniques can be found elsewhere [19]. After this procedure, animals had a biotelemetry transmitter implanted into the abdominal cavity, which allows online recording of locomotor activity and body temperature (for methodology, see [19]). After surgery, each rat received a single injection of Finadine $(0.1 \mathrm{ml} / \mathrm{kg})$ for pain reduction and of natrium-benzyl-penicilline (100.000 IU), and rats were allowed to recover. After full recovery of pre-operative body weight, animals were implanted under isoflurane $/ \mathrm{N}_{2} \mathrm{O}$ anesthesia with single jugular vein cannulas according to the methods described by Steffens [20]. Rats again received a single injection of Finadine $(0.1 \mathrm{ml} / \mathrm{kg})$ and a single dose of natrium-benzyl-penicilline (100.000 IU). Animals were allowed to recover for at least ten days before the actual experiments were started. During this period, placement of $\mathrm{i} 3 \mathrm{cv}$ cannulas was verified by assessing the drinking response to Angiotensin-II, according to techniques described elsewhere [21].

\section{Experimental Setup}

After having stabilized food intake, body temperature and locomotor activity for at least 3 days, animals were implanted subcutaneously with osmotic minipumps (Alzet
2002; Alza, Palo Alto, CA, pumping rate $0.55 \mu 1 /$ hour) under N2O-isoflurane anesthesia. Minipumps were connected with a polyethylene tube (PE50) to an injector permanently placed into the previously implanted $\mathrm{i} 3 \mathrm{cv}$ guide canula. The pumps and tubing were filled to deliver either the aspecific MC3/MC4-R antagonist, SHU9119 ([Ac-Nle ${ }^{4}, \mathrm{Asp}^{5}, \mathrm{D}-2-$ $\mathrm{Nal}^{7}$, Lys $\left.{ }^{10}\right]$-cyclo- $\alpha$-MSH (4-10) amide, M-4603, SigmaAldrich Chemie GmbH, Sternheim, Germany, $0.5 \mathrm{nmol} /$ day) or saline over a period of fourteen days. Assignment of rats to either i3cv SHU9119 $(n=14)$ or saline $(n=7)$ was such that the mean body weight among groups were similar. To account for food intake effects associated with reduced MC activity, half of the i3cv SHU9119-treated were pair-fed to the saline-treated control rats $(n=7)$, whereas the others were allowed to feed ad libitum. Each pair-fed animal receiving SHU9119 was given the same amount of food consumed by the saline-treated rat to which it was paired based on body weight at the day of the minipump implantation (day 0). Pair-fed animals received food 3 times per day; i.e., at the onset of the dark phase, 4 hours later, and at the end of the dark phase, to maintain a relatively normal feeding schedule.

Starting one week before the experiment, body weight and food intake were assessed daily. At the end of the experiment (day 14), animals were sacrificed by decapitation following brief $\mathrm{CO}_{2}$-anesthesia at approximately $3 \mathrm{hrs}$ after lights on. Trunk blood was collected in ice-cooled borosilicate tubes containing $500 \mu \mathrm{l}$ of aprotinin $(10.000 \mathrm{IU} / \mathrm{ml})$ and EDTA $(0.05 \mathrm{~g} / \mathrm{ml})$. Thereafter, the abdominal cavity was opened, and retroperitoneal and epidydimal fat pads were isolated and weighed. Blood samples were centrifuged (15 $\min , 2600 \mathrm{rpm}, 4^{\circ} \mathrm{C}$ ) and plasma samples were stored at -80 ${ }^{\circ} \mathrm{C}$ for determination of plasma levels of leptin, insulin, corticosterone and ACTH. Plasma levels of insulin, leptin and ACTH were measured by commercial radioimmunoassay kits (Linco Research; RI-13K, RL-83K and ACTH RIA kit, Nichols Institute Diagnostics, San Juan Capistrano, CA, USA). Plasma levels of corticosterone were measured using HPLC with UV detection according to Dawson et al., [22].

\section{Effects of CRH on HPA-Axis Activity, Thermogenesis, and Locomotor Behavior}

At days 7, 10, and 13 of the $i 3 \mathrm{cv}$ treatment, food hoppers were removed from the cages after light-onset. One-and-half hour later, rats were taken from their cage and shortly placed on the experimentor's lap, where they received an lateralcerebroventricular infusion (ilcv) (over a $30 \mathrm{sec}$. interval) with dimethylsulfoxide (DMSO, vehicle, $1 \mu 1 /$ rat) and an intraperitoneal (ip) injection of saline $(0.5 \mathrm{ml})$. On one of these days (according to a semi-random design), the DMSO served as vehicle for the synthetic glucocorticoid dexamethasone (DEX; 9 $\alpha$-fluoro-16 $\alpha$-methyl-prednisolone, D-1756, SigmaAldrich Chemie GmbH, Sternheim, Germany, $10 \mu \mathrm{g}$ in $1 \mu \mathrm{l}$ DMSO). On another day, not the ilcv injected DMSO, but the ip injected saline served as vehicle for DEX $(25 \mu \mathrm{g} / \mathrm{kg}$ rat). The ip and ilcv doses of DEX have been shown to cause sub-maximal down-regulation of ACTH responses to treatment with corticotropin-releasing hormone (CRH) [23]. On a third occasion, no DEX was added to the ip or ilcv injections, and thus served as control for the other conditions. Following these treatments, the ilcv cannula of rats was connected to infusion tubing (PE 20, length $40 \mathrm{~cm}$ ) of which the tip was filled with a solution of ovine CRH (American Pep- 
tide Company, Sunnyvale, California, USA), and they were connected to blood sampling tubing (PE 50, length $40 \mathrm{~cm}$ ) as well. Rats were subsequently left in their cages undisturbed, with their blood sampling and infusion tubing externalized out of their cages such that blood sampling and/or ilcv infusions could be performed remotely. Then, $1.5 \mathrm{hrs}$ after injections (i.e, $3 \mathrm{hr}$ after light onset), all animals were ilcv infused with CRH $(0.5 \mu \mathrm{g}$ dissolved in $1 \mu \mathrm{l}$ saline during a 30 -sec interval), with the exact time of infusion designated as $t=0$. Relative to $\mathrm{t}=0$, blood samples $(500 \mu \mathrm{l}$ each) taken at $\mathrm{t}=-10$, $-1,5,15$ and 60 minutes were collected in ice-cooled plastic tubes containing $50 \mu \mathrm{l}$ of aprotinin, $10.000 \mathrm{IU} / \mathrm{ml}$ and EDTA $0.05 \mathrm{~g} / \mathrm{ml}$. After centrifugation (15 min, 2600 rpm, $4{ }^{\circ} \mathrm{C}$ ) plasma samples were stored at $-80{ }^{\circ} \mathrm{C}$ for determination of plasma concentrations of $\mathrm{ACTH}$ and corticosterone. To avoid a decrease in total blood volume, each animal received $0.5 \mathrm{ml}$ of sterile saline after each blood sample was taken. Food hoppers were returned to the rat cages $2 \mathrm{hrs}$ after CRH injection.

Whereas the effects of ilcv infusion of CRH on HPA axis activity were assessed under conditions of peripheral, central, and no DEX pre-treatment, the effects of ilcv-infused $\mathrm{CRH}$ on body temperature and spontaneous activity were only assessed in the condition without DEX pre-treatment. During the 2 hours before CRH infusion, and until $2 \mathrm{hrs}$ after infusion, average body temperature over 5 -min periods and cumulative spontaneous activity over two hours were assessed with the Data-Quest Biotelemetry system.

\section{Effects of CRH on Ingestive Behavior}

Different groups of rats only equipped with combined $\mathrm{i} 3 \mathrm{cv}-$ and ilcv-cannulation, but without blood sampling catheters and biotelemetry transmiters, were either given minipumps filled to deliver i3cv saline $(n=5)$ or SHU9119 $(0.5 \mathrm{nmol} /$ day, $\mathrm{n}=6)$ according to the same techniques mentioned above. Experiments were conducted after food intake in the i3cv SHU9119-treated rats stabilized at a higher level. On two separate days with at least 3 days between successive experiments, food hoppers were removed from the cages 2 hrs before the onset of the dark phase and returned to the cages at lights off. One hour before the dark phase on these days, rats were ilcv infused with saline $(1 \mu \mathrm{l})$ or CRH $(0.5$

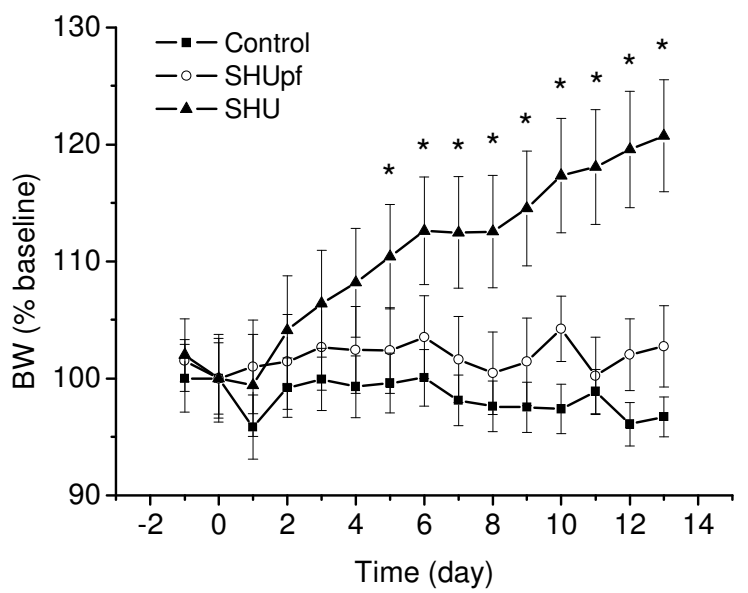

$\mu \mathrm{g} / \mu \mathrm{l}$ saline) according to a latin-square design, allowing each animal to act as its own control. Weight of food hoppers was assessed just before returning to them to the cages (at lights off, $\mathrm{t}=0 \mathrm{hr}$ ), and also at $\mathrm{t}=4,12$ and $24 \mathrm{hrs}$. At the end of $\mathrm{i} 3 \mathrm{cv}$ treatment periods, rats were anaesthetized $3 \mathrm{hrs}$ after lights on, and decapitated. Brains were removed and frozen on crushed dry ice, and stored at $-80{ }^{\circ} \mathrm{C}$ until being cut on a cryotome for assessment of canula placements (which were all correct).

\section{Statistical Analysis}

Results are presented as means \pm SEM, repeated measures analysis of variance (ANOVA) was used to assess temporal and treatment effects on food intake and body weight, and on neuroendocrine and thermogenic responses of CRH. One-way ANOVA was used to assess treatment effects on end-point neuroendocrine and metabolic parameters. Data were considered significant if levels of $p<0.05$.

\section{RESULTS}

\section{Effects of i3cv SHU9119 Treament on Body Weight and Food Intake}

The effects of i3cv SHU9119 and saline treatment on body weight and food intake of rats are shown in Fig. (1). Results are depicted as \% change compared to average body weight or food intake of days -1 and 0 . Food intake in the i3cv SHU9119-treated animals was already significantly increased $(p<0.05)$ on the first day following pumpimplantation relative to saline-treated controls. This difference in food intake became larger each next day until a plateau of about $200 \%$ of initial intake was reached at day 7 . Significant increases in body weight $(\mathrm{p}<0.05)$ were found in i3cv SHU9119-treated rats from day 5 on. Body weights of i3cv SHU9119-treated rats that were pair-fed to salinetreated rats were indifferent from saline-treated animals. Relative to i3cv saline treatment, the effects of i3cv SHU9119 treatment on body weight were associated with increases in retroperitoneal and epidydimal fat pad weight, and elevated plasma leptin and insulin levels. No differences were found in the level of circulating corticosterone. Consistent with previous findings [19] were the observations that i3cv SHU9119 treatment increased abdominal fat weight and

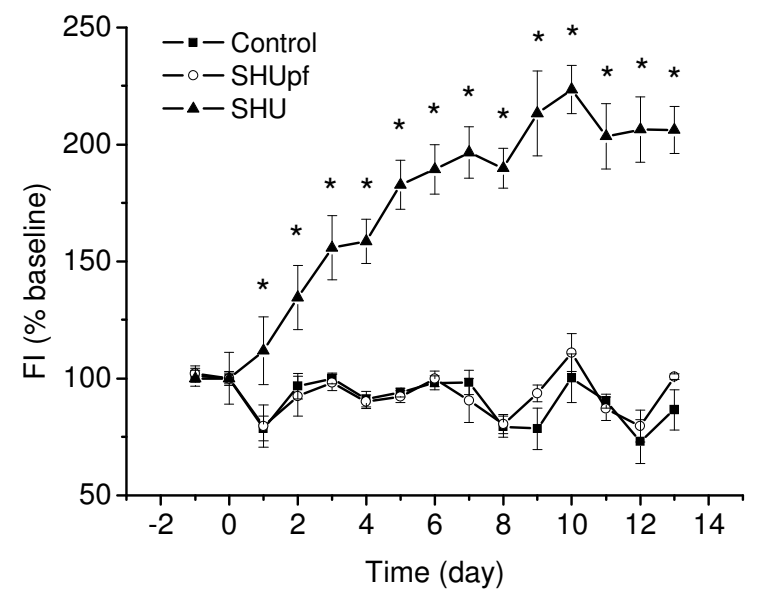

Fig. (1). Changes in body weight (left panel) and food intake (right panel) in rats that were either i3cv infused with saline (Control, $\mathrm{n}=7$ ) or SHU9119 (SHU, n=7). A third group consisted of i3cv SHU9119-treated rats were pair-fed to saline-treated controls (SHUpf, n=7). Minipump-implantation was performed on day 0 . Results are depicted as \% change compared to baseline. Asterisks denote sigificant differences $(\mathrm{p}<0.05)$ compared to controls. 
Table 1. Plasma concentrations of leptin and insulin, and weights of abdominal fat pads (total of retroperitoneal and epidydimal fatpads) of rats at the end of 14-day i3cv treatment with saline (Control, n=7) or SHU9119 (SHU, n=7). A third group of rats was i3cv-infused with SHU9119, but were pair-fed (SHUpf, $n=7$ ) to saline-treated controls.

\begin{tabular}{|llll|}
\hline Treatment & Control & SHU & SHUpf \\
\hline \hline Leptin $(\mathrm{ng} / \mathrm{ml})$ & $2.98 \pm 0.47$ & $30.65 \pm 3.10^{* * *}$ & $6.14 \pm 0.67^{*}$ \\
Insulin $(\mathrm{ng} / \mathrm{ml})$ & $2.63 \pm 0.16$ & $9.82 \pm 1.11^{* *}$ & $3.30 \pm 0.38$ \\
Abd. fat pads $(\mathrm{g})$ & $7.44 \pm 0.49$ & $17.60 \pm 1.35^{* *}$ & $9.39 \pm 0.66^{*}$ \\
\hline
\end{tabular}

Values depicted as means \pm SEM. $* \mathrm{p}<0.05, * * \mathrm{p}<0.01$ and $* * * \mathrm{p}<0.001$ compared to vehicle-treated controls.

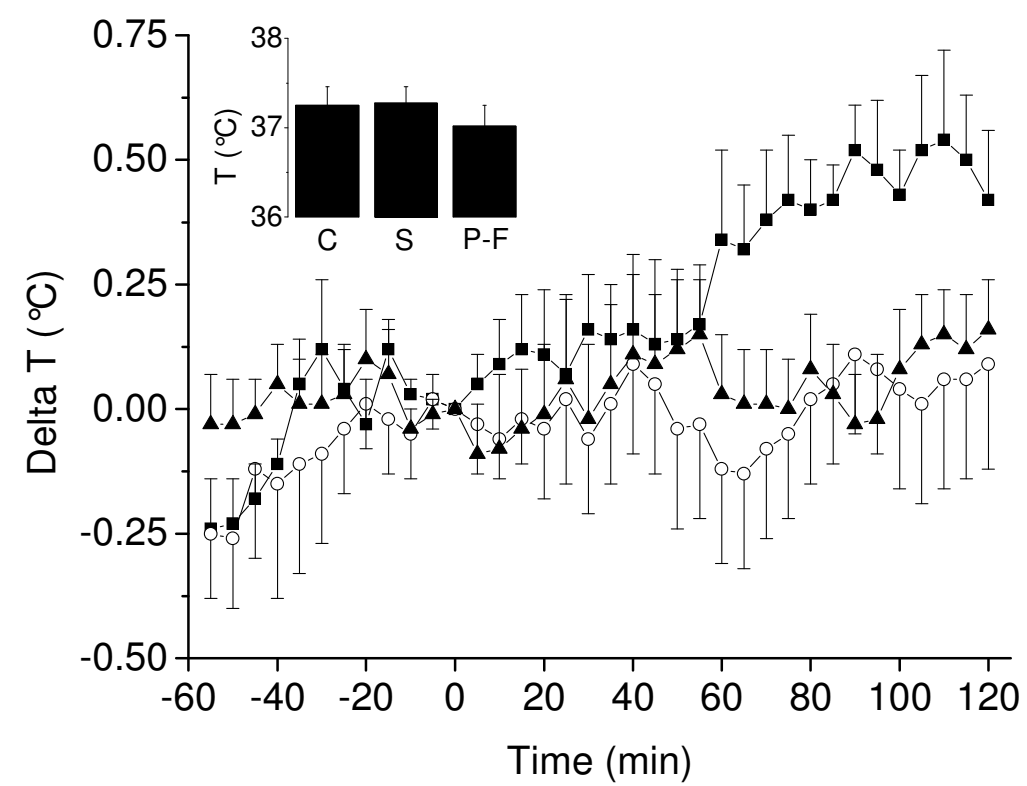

Fig. (2). Effects of $\mathrm{CRH}$ administration $(0.5 \mu \mathrm{g}, \mathrm{t}=0)$ on body temperature (Celcius) of i $3 \mathrm{cv}$ saline-treated rats (open circles, $\mathrm{n}=7$ ), i3cv SHU9119-treated rats (black triangles, $n=7$ ), and i3cv SHU9119-treated rats pair-fed to controls (black squares, $n=7$ ). The effects of CRH administration on body temperature are presented as change from $\mathrm{t}=0$ min [Delta $\left.\mathrm{T}\left({ }^{\circ} \mathrm{C}\right)\right]$. The insert shows average temperature over a period of $2 \mathrm{hrs}$ prior to $\mathrm{CRH}$ administration in the three $\mathrm{i} 3 \mathrm{cv}$ treatment groups. Values are depicted as means $\pm \mathrm{SEM}$.

plasma leptin levels when these animals were pair fed to saline-treated controls, and plasma levels of insulin were only elevated in SHU9119-treated ad libitum feeding rats (see Table 1).

\section{Effects of i3cv SHU9119 Treatment on CRH-Mediated Stimulation of Thermogenesis and Locomotor Behavior}

Effects of ilcv CRH administration on body temperature in the $13 \mathrm{cv}$ saline and $\mathrm{i} 3 \mathrm{cv}$ SHU9119-treated groups are shown in Fig. (2). The insert in Fig. (2) shows the basal average body temperature over $2 \mathrm{hr}$ prior to the ilcv CRH infusion, indicating that there was no difference among the $\mathrm{i} 3 \mathrm{cv}$ saline, i3cv SHU9119 ad libitum and i3cv SHU9119 pair-fed rats. Ilcv $\mathrm{CRH}$ infusion (at $\mathrm{t}=0 \mathrm{~min}$ ) caused significant increases ( $p<0.05$ from $t=60$ min onwards) in body temperature relative to baseline in $i 3 \mathrm{cv}$ saline-treated rats, an effect that was not observed in both i3cv SHU9119-treated groups of rats. Moreover, i3cv SHU9119-treated ad libitum feeding rats had significantly lower body temperature over time (from $\mathrm{t}=0-120 \mathrm{~min}$ ) following ilcv $\mathrm{CRH}$ infusion than $\mathrm{i} 3 \mathrm{cv}$ saline-treated rats $(p<0.05)$. The difference between $i 3 c v$ saline-treated and i3cv SHU9119-treated pair-feeding rats did not attain statistical significance.
The effects of ilcv CRH administration in the three i3cv treatment groups on cummulative locomotor activity are shown in Table 2. All comparisons of basal and CRHstimulated changes of locomotor activity in i3cv SHU9119. treated groups (ad libitum or pair-feeding) relative to the i3 cv saline-treated group did not attain significance. However, basal cummulative locomotor activity over $2 \mathrm{hrs}$ prior to ilcv CRH administrationwas significantly higher $(\mathrm{p}<0.05)$ in the i3cv SHU9119 pair-feeding rats than in the $13 \mathrm{cv}$ SHU9119 ad libitum feeding rats. The percentual increase in cummulative locomotor activity following $\mathrm{i} 3 \mathrm{cv} \mathrm{CRH}$ administration relative to baseline, tended $(p=0.06)$ to be increased in the $i 3 \mathrm{cv}$ saline-treated rats relative to $i 3 \mathrm{cv}$ SHU9119-treated ad libitum feeding animals.

\section{Effects of i3cv SHU9119 Treatment on CRH-Mediated Stimulation of HPA-Axis Activity}

Effects of ilcv CRH administration on plasma ACTH levels of rats in the different chronic $13 \mathrm{cv}$ treatment groups are shown in Fig. (3). Relative to controls, i3cv SHU9119treated pair-fed rats had a markedly suppressed ACTH response following ilcv CRH administration. There was also a slight decrease in i3cv SHU9119-treated ad libitum feeding animals, but this reduction did not attain statistical signifi- 
Table 2. Cumulative locomotor activity during $2 \mathrm{hr}$ basal and $2 \mathrm{hr}$ post CRH administration (0.5 $\mu \mathrm{g})$ as well as percentual (\%; [Post/Basal]x 100) increases in locomotor activity in i3cv saline-treated rats (Control, $n=7)$, i3cv SHU9119-treated rats (SHU, n=7), or i3cv SHU9119-treated rats pair-fed to controls (SHUpf, $n=7$ ).

\begin{tabular}{|llll|}
\hline Treatment & Control & SHU & SHUpf \\
\hline Basal & $171.8 \pm 29.4$ & $111.7 \pm 33.5$ & $295.5 \pm 27.4^{*}$ \\
Post & $729.4 \pm 144.0$ & $216.5 \pm 85.5$ & $666.3 \pm 152.5$ \\
$\%$ & $424.6 \pm 77.5$ & $193.8 \pm 24.5$ & $225.5 \pm 39.7$ \\
\hline
\end{tabular}

Values depicted as means \pm SEM. Asterisks denote $\mathrm{p}<0.05$ compared to SHU9119-treated ad libitum feeding rats.
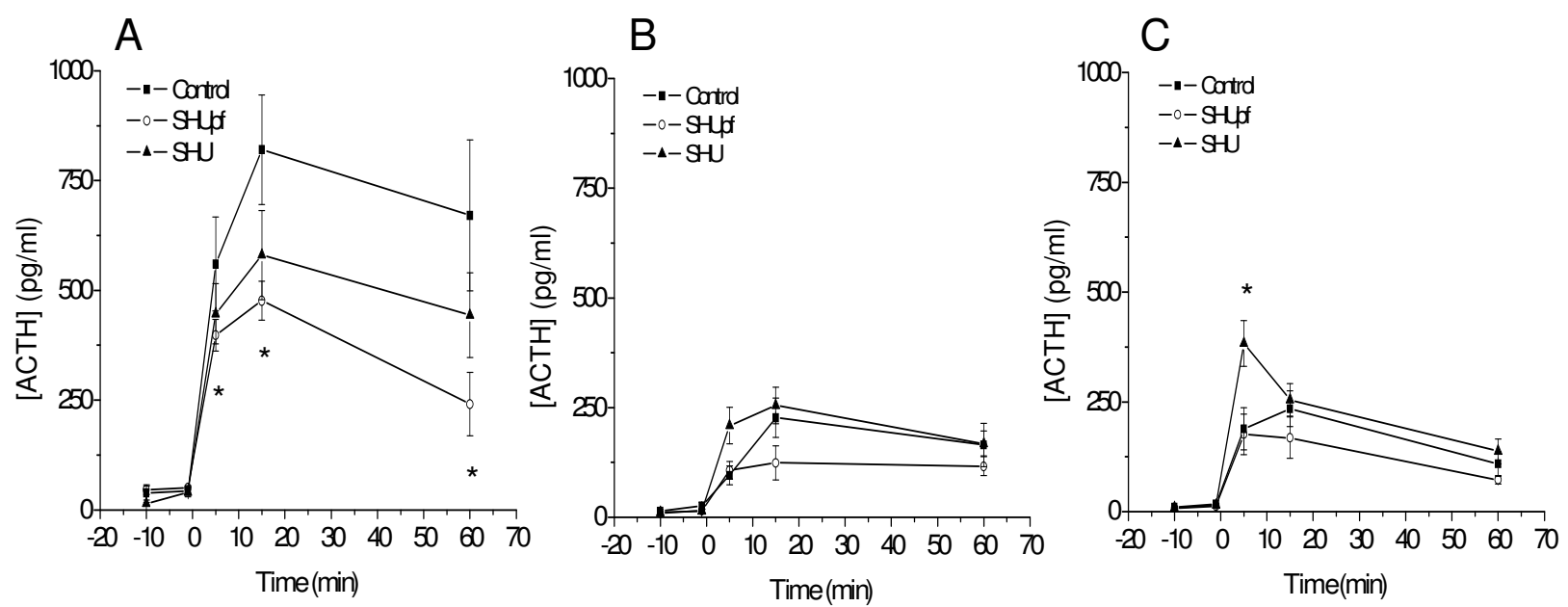

Fig. (3). Plasma ACTH levels in rats after $\mathrm{CRH}$ administration $(0.5 \mu \mathrm{g}, \mathrm{t}=0)$ that were chronically $\mathrm{i} 3 \mathrm{cv}$ infused with saline (Control, $\mathrm{n}=7)$, SHU9119 (SHU, n=7), or SHU9119 but pair-fed to saline-treated controls (SHUpf, n=7). Before CRH administration, all rats were either pre-treated with vehicle (panel A) or dexamethasone given centrally (panel B) or dexamethasone given peripherally (panel C). Values depicted as means \pm SEM. Asterisks denote $\mathrm{p}<0.05$ compared to controls.

cance. In order to investigate whether the decreased ACTH response was due to increased glucocorticoid feedback, ilcv $\mathrm{CRH}$ effects on plasma ACTH responses were also performed with prior ilcv (Fig. 3b) and ip (Fig. 3c) DEX treatment. In both DEX pre-treatment conditions, ACTH responses were suppressed relative to the situation without DEX pretreatment. Under the conditions of ilcv (Fig. 3b) or ip (Fig. 3c) DEX pretreatment, however, CRH-induced ACTH responses were not more potently suppressed in $\mathrm{i} 3 \mathrm{cv}$ SHU9119-treated rats compared to the $13 \mathrm{cv}$ saline-treated control group.. In fact, in the ip DEX condition, ACTH levels in the i3cv SHU9119-treated ad libitum feeding animals were higher relative to the controls (significantly elevated at $\mathrm{t}=5 \mathrm{~min}, \mathrm{p}<0.05$ ), demonstrating a reduced suppression of ACTH level by DEX in i3cv SHU9119-treated animals relative to $i 3 \mathrm{cv}$ saline treatment.

Effects of ilcv CRH administration on plasma corticosterone levels of rats in the different chronic i $3 \mathrm{cv}$ treatment groups are shown in Fig. (4). Unlike the differences of plasma ACTH responses among groups without DEX pretreatment, ilcv CRH administration in rats in the three different $\mathrm{i} 3 \mathrm{cv}$ treatment groups caused similar increases in plasma levels of corticosterone (Fig 4a). Central (Fig 4b) as well as peripheral (Fig 4c) DEX pre-treatment generally caused reductions in plasma corticosterone levels upon ilcv CRH administration compared to non-DEX treated rats. These reductions were largely attributed to a fall in plasma corticosterone level already at baseline $(\mathrm{t}=-11$ and $-1 \mathrm{~min})$. Whereas the corticosterone responses following ilcv CRH administration were not different among the $\mathrm{i} 3 \mathrm{cv}$ treatment groups with ilcv DEX pre-treatment, plasma levels of corticosterone in the ip DEX pre-treatment group following ilcv-administered CRH were significantly reduced in the i3cv SHU9119treated ad libitum feeding (at $\mathrm{t}=15 \mathrm{~min}$ ) and i3cv SHU9119. treated pair-fed (at $\mathrm{t}=60 \mathrm{~min}$ ) rats relative to controls.

To assess the magnitude by which DEX was able to suppress ACTH and corticosterone responses to ilcv $\mathrm{CRH}$ administration relative to the condition without DEX pretreatment, area-under-the-curves (AUCs) of plasma ACTHand corticosterone responses were expressed as \% suppression compared to vehicle pre-treatment. These relative suppressions by DEX of plasma ACTH- and corticosterone levels are depicted in Fig. (5). Rats receiving chronic i3cv SHU9119 treatment had significantly reduced suppression of the CRH-mediated ACTH response by ilcv DEX pretreatment, and a near-significantly $(\mathrm{p}=0.07)$ reduced suppression following ip DEX pre-treatment (Fig. 5A). In the case of the corticosterone response to ilcv-infused CRH, ip DEX pre-treatment produced a stronger suppression $(\mathrm{p}<0.05)$ in the $13 \mathrm{cv}$ SHU9119-treated pair-feeding rats, and a nearsignificantly stronger $(p=0.06)$ suppression in the $i 3 \mathrm{cv}$ SHU9119-treated ad libitum feeding rats relative to $\mathrm{i} 3 \mathrm{cv}$ saline-infused controls (Fig. 5B). CRH-mediated increases in plasma corticosterone levels were not (differently) suppressed by ilcv DEX treatment. 

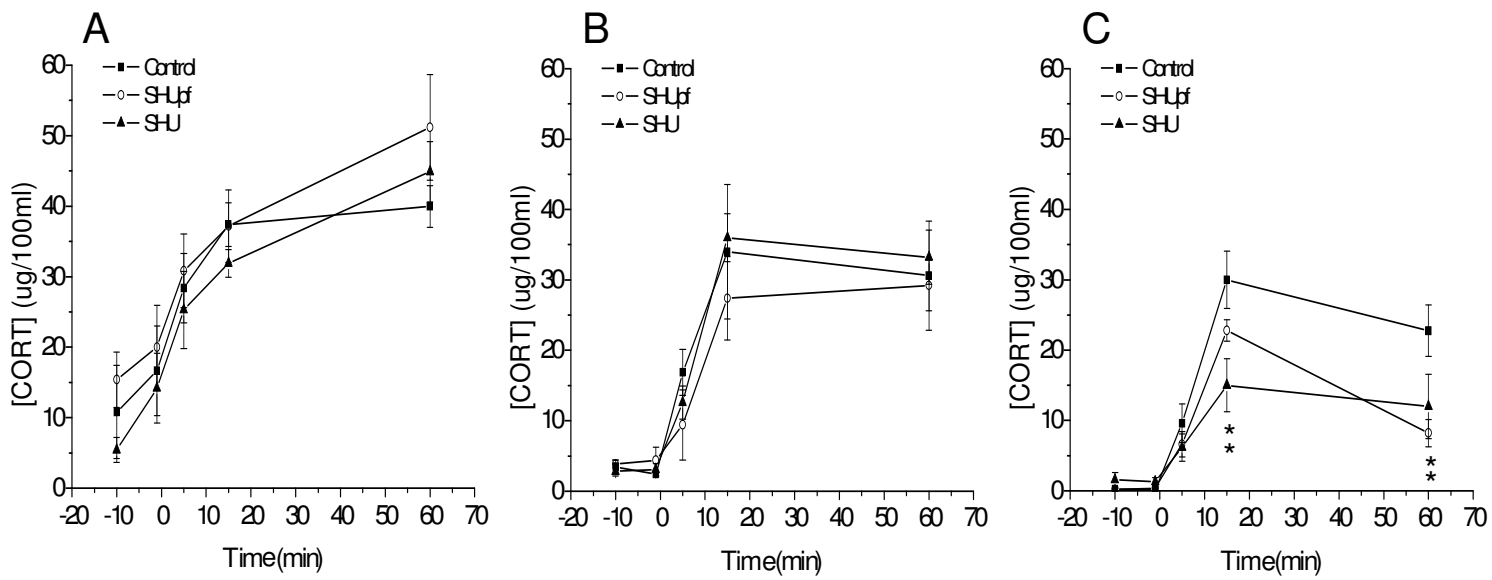

Fig. (4). Plasma corticosterone levels in rats after $\mathrm{CRH}$ administration $(0.5 \mu \mathrm{g}, \mathrm{t}=0)$ that were chronically i3cv infused with saline $(\mathrm{Control}$, $\mathrm{n}=7$ ), SHU9119 (SHU, n=7), or SHU9119 but pair-fed to saline-treated controls (SHUpf, n=7). Before CRH administration, all rats were either pre-treated with vehicle (panel A), dexamethasone given centrally (panel B), or dexamethasone given peripherally (panel C). Values are depicted as means \pm SEM. Asterisks denote $\mathrm{p}<0.05$ compared to controls.
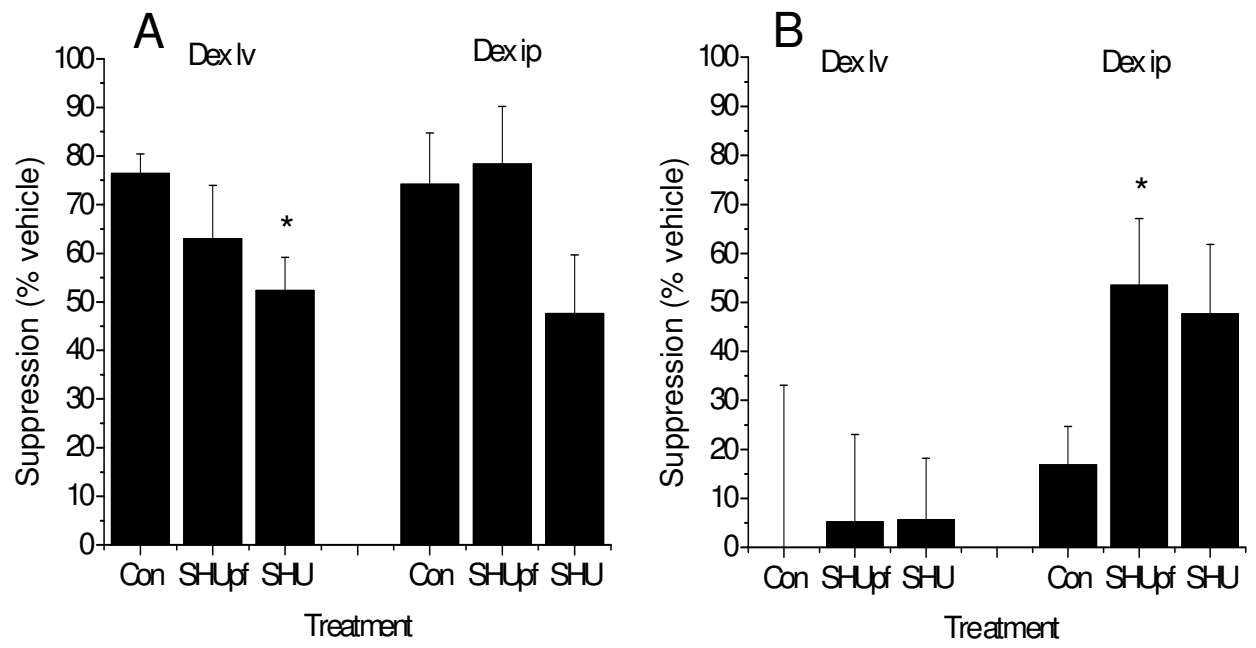

Fig. (5). Relative suppression of plasma ACTH responses (panel A) and plasma corticosterone responses (panel B) after central (Dex lv) or peripheral (Dex ip) dexamethasone pre-treatment in response to $\mathrm{CRH}$ administration $(0.5 \mu \mathrm{g})$ in rats with i3cv saline treatment (Con, $\mathrm{n}=7)$, i3cv SHU9119 treatment (SHU, n=7) or i3cv SHU9119 treatment and pair-fed to controls (SHUpf, $n=7$ ). Values depicted as means \pm SEM. Asterisks denote $\mathrm{p}<0.05$ compared to controls.

\section{Effects of i3cv SHU9119 Treatment on CRH-Mediated Anorexia}

In different i3cv saline-treated and i3cv SHU9119-treated animals as those used above, the effect of ilcv CRH administration was investigated on food intake relative to ilcvinfused saline. The effects of i3cv SHU9119 treatment and $\mathrm{i} 3 \mathrm{cv}$ saline treatment on food intake and body weight were comparable to those mentioned above. The anorexigenic effects of CRH relative to saline were assessed when food intake in the i3cv SHU9119-treated rats stabilized at a high level; i.e., between days 7 and 11 of treatment. Since food intake in the i3cv SHU9119-treated rats was much larger relative to $\mathrm{i} 3 \mathrm{cv}$ saline-treated controls, food intake suppression by ilcv CRH infusion was indicated as a percentual reduction from ilcv saline infusion (Fig. 6). It was observed that the percentual suppression of food intake at $4 \mathrm{hrs}$ in the dark phase by CRH in the i3cv SHU9119-treated rats was at the threshold of being significantly larger than that in the $\mathrm{i} 3 \mathrm{cv}$ saline-treated rats $(\mathrm{p}=0.05)$. At $\mathrm{t}=12$ and $\mathrm{t}=24$ hours, no differences were observed between groups (data not shown).

\section{DISCUSSION}

Administration of CRH into the cerebral ventricular system of rats caused marked reductions in food intake and increases in body temperature, locomotor activity, and increased activity of the HPA axis. These responses are presumably mediated by CRH acting on post-synaptic CRH1 and CRH2 receptors in several projection sites, but also by a stimulatory effect on paraventricular hypothalamic CRH neurons, from which many of these projections originate $[24,25]$. The present study investigated the involvement of brain melanocortin receptors (MC-Rs) in these responses. We therefore investigated the effects of lateral cerebroventricular (ilcv) CRH infusion on above-mentioned parameters in rats that were chronically infused into the third cerebral ventricle $(\mathrm{i} 3 \mathrm{cv})$ with the unspecific $\mathrm{MC} 3 / 4-\mathrm{R}$ antagonist, SHU9119, and in i3cv saline-treated controls. Overall, the effects of MC-R antagonism on $\mathrm{CRH}$-induced changes in food intake, HPA axis activity and body temperature were not secondary to increased body weight, since i3cv SHU9119-treated rats pair-fed to controls generally showed similar responses as i3cv SHU9119-treated rats fed ad libi- 


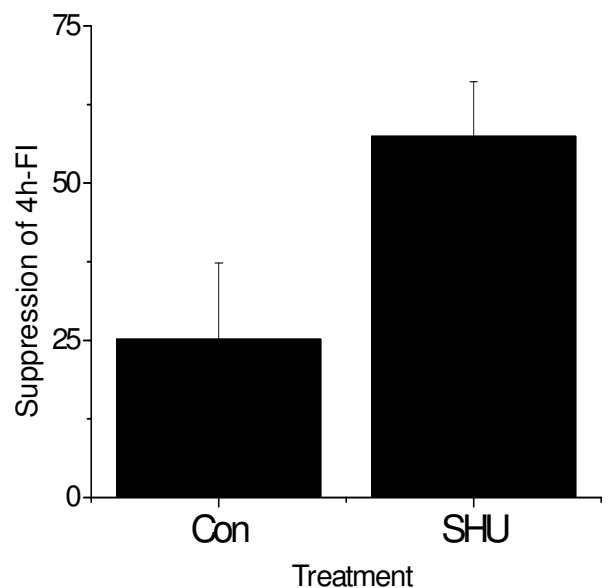

Fig. (6). Percentual suppression of 4-hr food intake after CRH administration $(0.5 \mu \mathrm{g})$ in rats that were chronically i $3 \mathrm{cv}$ infused with saline (Con, $n=5)$ or with SHU9119 (SHU, n=6). Data are expressed as \% suppression of food intake by $\mathrm{CRH}$ relative to saline treatment. SHU-CRH vs. control-CRH, $\mathrm{p}=0.05$.

tum. With respect to food intake, we could reinforce the findings by Vergoni et al., [15] that MC-R blockade does not impair the anorexigenic efficacy of CRH. In fact, we found that i3cv SHU9119-treated rats had a strong tendency towards being more sensitive to the anorexigenic effects of CRH over the first few hours in the dark phase. Such an effect was previously observed in mice with a targeted mutation in the DNA encoding for MC-R4 as well [26], and would be consistent with the notion that CRH neurons normally receive stimulatory input from $\mathrm{MC}$ neurons under conditions of a positive energy balance. With respect to HPA axis activity and thermogenesis, a completely different picture emerged on the contribution of MC-Rs in CRH effects. In light of our previous findings that i3cv SHU9119-treated rats have an increased expression of $\mathrm{CRH}$ in PVN neurons [19], ilcv CRH injection might have been expected to cause increased thermogenesis [6,7] and HPA axis activity [14]. However, the plasma ACTH response and the increase in body temperature following $\mathrm{CRH}$ were markedly suppressed in $\mathrm{i} 3 \mathrm{cv}$ SHU9119-treated rats. The finding that CRHmediated thermogenesis is impaired by central immunoneutralization of proopiomelanocortin precursors is in agreement with our findings [16]. One possible mechanism explaining these effects is that MC-Rs are located on synaptic terminals of $\mathrm{CRH}$ neurons in the $\mathrm{ME}$ and sympathetic brain stem/spinal cord regions involved in thermogenesis, and that tonic activity on these $\mathrm{MC}-\mathrm{Rs}$ is required for increased $\mathrm{CRH}$ release or action in the $\mathrm{ME}$ and brain stem/spinal cord. While the presence of the MC-Rs on CRH terminals (either pre-or post-synapticaly) has not yet been identified, there is evidence that neuronal fibers containing $\mathrm{CRH}$ and those that contain melanocortins are closely associated in forebrain as well as hindbrain regions [27], allowing us to speculate that such an interaction may indeed exist.

Another mechanism by which MC-R blockade could potentially blunt CRH-mediated increases in plasma ACTH levels is that glucocorticoid feedback is increased in $\mathrm{i} 3 \mathrm{cv}$ SHU9119-treated rats. This mechanism could potentially also account for reduced CRH-mediated thermogenesis in i3cv SHU9119-treated rats [28]. To investigate whether increased glucocorticoid feedback underlies the observed phe- nomena on $\mathrm{CRH}$-induced activation of ACTH release, ilcv $\mathrm{CRH}$ effects on ACTH responses were investigated with central as well as peripheral pre-treatment of the synthetic glucocorticoid receptor (GR) agonist, dexamethasone (DEX). Opposite to a potential upregulation of glucocorticoid feedback explaining the lower CRH-induced ACTH response, however, we observed that the degree of suppression by central DEX on the CRH-mediated ACTH response was significantly reduced in $13 \mathrm{cv}$ SHU9119-treated rats. In support of these findings is our recent observation that $i 3 \mathrm{cv}$ SHU9119-treated rats have a significant reduction in GR density in the PVN (van Dijk et al. in preparation). Downregulation of GR in the PVN would imply an increased expression of CRH mRNA in the PVN [29], and that is exactly what we previously found in i3cv SHU9119-treated rats [19]. These data are also consistent with the findings by Rigter et al., [30] showing that MC-R activation upregulates GR binding sites in several brain regions. In addition, however, we found that the CRH-mediated ACTH response appeared to be near-significantly suppressed upon peripheral DEX pre-treatment. This indicates that GR feedback at the level of the pituitary would be lower in SHU9119-treated rats. Since i3cv SHU9119-treated pair-fed rats did not show any down-regulation of GR feedback with plasma ACTH as read-out parameter, the action by which i3cv SHU9119 treatment causes these effects is probably indirect. It might be argued, for example, that leptin being elevated in the SHU9119-treated ad libitum feeding rats, causes a downregulation of GR. Although leptin has previously been shown to upregulate PVN GR density and expression in the neonatal stage [31], opposite effects on GR density in the neonatal vs. adult rat have previously been reported for other treatments (e.g., [32,33]).

Despite the reduction of the CRH-induced plasma ACTH response in $\mathrm{i} 3 \mathrm{cv}$ SHU9119-treated rats relative to controls, this did not result in lower plasma levels of corticosterone. When lower levels of ACTH result in similar corticosterone responses, this would imply that reduced melanocortin transmission increases the sensitivity of the adrenal cortex to ACTH, perhaps analogous to a mechanism previously desribed by Buijs et al., [34]. If any, this effect must be quite robust since the hyperleptinemia in i3cv SHU9119-treated rats would normally oppose glucocorticoid secretion [35] (but see $[11,33]$ ). As opposed to the reduced suppression by DEX of the $\mathrm{CRH}$-induced ACTH responses in $\mathrm{i} 3 \mathrm{cv}$ SHU9119-treated rats, peripheral DEX pre-treatment caused a markedly enhanced suppression of the CRH-mediated corticosterone response in i3cv SHU9119-treated rats, irrespective of pair-feeding or ad libitum feeding. These effects were not observed with central DEX pretreatment. Although we are not aware of any study assessing the presence of GR in the adrenal cortex, this would imply that endogenous corticosterone may potentially down-regulate its own release more potently through such an ultra-short feed-back loop in animals i3cv treated with SHU9119. Collectively, these mechanisms would attenuate the activity of the HPA axis in animals with i3cv SHU9119 treatment, despite upregulated expression of CRH that we previously found with SHU9119 treatment [19].

Taken together, chronic blockade of MC receptors does not inhibit $\mathrm{CRH}$-induced anorexia, but blunts $\mathrm{CRH}$-induced thermogenesis and HPA axis activity. These data therefore 
indicate that $\mathrm{MC}$ receptors act downstream from CRH effects on ACTH release and thermogenesis, but not downstream from CRH effects on feeding. This study additionally demonstrates that increased GR feed-back is not responsible for the reduced efficacy by which CRH can increase plasma ACTH levels in i3cv SHU9119-treated rats, but increased GR feedback in i3cv SHU9119-treated rats at the level of the adrenal cortex could limit glucocorticoid secretion on the long-term. We propose that - in addition to be located on CRH-containing neuronal cell bodies in the PVN [14], and which may be involved in feeding behavior- MC-Rs may also be present on neuronal terminals (either pre- or postsynaptically, or both) where they can fine-tune the stimulatory effect of CRH on ACTH release. Such an effect may be anticipated for CRH-induced thermogenesis via sympathetic preganglionics as well. Indeed, melanocortin receptor activity has been associated with regulation of sympathetic tone [36], which is an important mechanism to stimulate thermogenesis. Thus, the effects of SHU9119 on CRH responsiveness may involve suppression of MC-R's stimulatory effect on sympathetic outflow, for instance at the level of the adrenal gland and brown adipose tissue, but apparently not for $\mathrm{CRH}$-induced anorexia. The function of this dissociation is yet unknown, but considering the fact that the endogenous inverse agonist agouti-related protein (AgRP) could serve similar actions as SHU9119 [37], and mutations in MC-R4s are found relatively frequently at least in the human population [38], the proposed regulatory influences of MC-R activity on CRH efficacy might have adaptive behavioral and physiological relevance. Such relevance may be found, for example, in situations in which an emotional/physical stressor calls forth a temporal activation of the CRH system in thrifty animals due to low activity of the MC system. According to the data in the present study, this would be expected to induce a strong CRH-mediated decline of energy intake (for example, necessary to focus on external stimuli, rather than on feeding), but at the same it would minimize wasting of energy through reduced efficacy of CRH to stimulate thermogenesis and HPA axis activity.

\section{ACKNOWLEDGMENTS}

The authors would like to thank Jan Bruggink for excellent technical assistance. This research was funded by the Dutch Foundation for Scientific Research (NWO-MW 90939-193), the Royal Academia for Arts and Sciences (KNAW), the Neuropeptide Research Foundation in The Netherlands, and by the Groningen School for Behavioral and Cognitive Neurosciences (BCN).

\section{CONFLICT OF INTEREST}

None declared.

\section{REFERENCES}

[1] Richard D, Lin Q, Timofeeva E. The corticotropin-releasing factor family of peptides and CRF receptors: their roles in the regulation of energy balance. Eur J Pharmacol 2002; 440 (2-3): 189-97.

[2] Rothwell NJ. Central effects of CRF on metabolism and energy balance. Neurosci Biobehav Rev 1990; 14 (3): 263-71.

[3] Bruhn TO, Plotsky PM, Vale WW. Effect of paraventricular lesions on corticotropin-releasing factor (CRF)-like immunoreactivity in the stalk-median eminence: studies on the adrenocorticotropin response to ether stress and exogenous CRF. Endocrinology 1984; 114 (1): 57-62.

[4] Dallman MF, Akana SF, Strack AM, Hanson ES, Sebastian RJ. The neural network that regulates energy balance is responsive to glucocorticoids and insulin and also regulates HPA axis responsivity at a site proximal to CRF neurons. Ann N Y Acad Science 1995; 771: 730-42.

[5] Overton JM, Fisher LA. Differentiated hemodynamic responses to central versus peripheral administration of corticotropin-releasing factor in conscious rats. J Auton Nerv Syst 1991; 35 (1): 43-51.

[6] LeFeuvre RA, Rothwell NJ, Stock MJ. Activation of brown fat thermogenesis in response to central injection of corticotropin releasing hormone in the rat. Neuropharmacology 1987; 26 (8): 1217-21.

[7] Arase K, York DA, Shimizu H, Shargill N, Bray GA. Effects of corticotropin-releasing factor on food intake and brown adipose tissue thermogenesis in rats. Am J Physiol 1988; 255 (3 Pt 1): E255E9.

[8] Hotta M, Shibasaki T, Yamauchi N, et al. The effects of chronic central administration of corticotropin-releasing factor on food intake, body weight, and hypothalamic-pituitary-adrenocortical hormones. Life Sci 1991; 48 (15): 1483-91.

[9] Buwalda B, de Boer SF, Van Kalkeren AA, Koolhaas JM. Physiological and behavioral effects of chronic intracerebroventricular infusion of corticotropin-releasing factor in the rat. Psychoneuroendocrinology 1997; 22 (5): 297-309.

[10] van Dijk G, Seeley RJ, Thiele TE, et al., Tenenbaum R, Baskin DG, Woods SC, Schwartz MW. Metabolic, gastrointestinal, and CNS neuropeptide effects of brain leptin administration in the rat. Am J Physiol 1999; 276 (5 Pt 2): R1425-R33.

[11] van Dijk G, de Vries K, Nyakas C, et al. Anorexigenic efficacy of leptin, but not of the brain melanocortin pathway, predicts proneness for diet-induced obesity in rats. Endocrinology 2005; 146(12): 5247-56.

[12] Masaki T, Yoshimichi G, Chiba S, et al. Corticotropin-releasing hormone-mediated pathway of leptin to regulate feeding, adiposity, and uncoupling protein expression in mice. Endocrinology 2003; 144 (8): 3547-454

[13] Seeley RJ, Yagaloff KA, Fisher SL, et al. Melanocortin receptors in leptin effects. Nature 1997; 390 (6658): 349.

[14] Lu XY, Barsh GS, Akil H, Watson SJ. Interaction between alphamelanocyte-stimulating hormone and corticotropin-releasing hormone in the regulation of feeding and hypothalamo-pituitaryadrenal responses. J Neuroscience 2003; 23 (21): 7863-72.

[15] Vergoni AV, Bertolini A, Wikberg JE, Schioth HB. Corticotropinreleasing factor (CRF) induced anorexia is not influenced by a melanocortin 4 receptor blockage. Peptides 1999; 20 (4): 509-13.

[16] Rothwell NJ, Hardwick A, LeFeuvre RA, Crosby SR, White A. Central actions of CRF on thermogenesis are mediated by proopiomelanocortin products. Brain Res 1991; 541 (1): 89-92.

[17] Von Frijtag JC, Croiset G, Gispen WH, Adan RA, Wiegant VM. The role of central melanocortin receptors in the activation of the hypothalamus-pituitary-adrenal-axis and the induction of excessive grooming. Br J Pharmacol 1998; 123 (8): 1503-8.

[18] Paxinos G, Watson Ch. The rat brain in stereotaxic coordinates. 2nd ed, 1986 Academic Press Australia.

[19] Adage T, Scheurink AJ, de Boer SF, et al. Hypothalamic, metabolic, and behavioral responses to pharmacological inhibition of CNS melanocortin signaling in rats. J Neurosci 2001; 21(10): 363945.

[20] Steffens AB. A method for frequent sampling of blood and continuous infusions of fluids in the rat without disturbing the animals. Phys Beh 1969; 4: 833-6.

[21] Van Dijk G, Thiele TE, Donahey JCK, et al. Central infusions of leptin and GLP-1 (7-36) amide differentially stimulate c-FLI in the rat brain. Am J Physiol 1996; 271: R1096-R100.

[22] Dawson R, Kontur P, Monjanr A. High-performance liquid chromatography (HPLC) separation and quantitation of endogenous glucocorticoids after solid-phase extraction from plasma. Horm Res 1984; 20: 89-94.

[23] Buwalda B, de Boer SF, Schmidt ED, et al. Long-lasting deficient dexamethasone suppression of hypothalamic-pituitaryadrenocortical activation following peripheral CRF challenge in socially defeated rats. J Neuroendocrinol 1999; 11 (7): 513-20.

[24] Jezova D, Ochedalski T, Glickman M, Kiss A, Aguilera G. Central corticotropin-releasing hormone receptors modulate hypothalamicpituitary-adrenocortical and sympathoadrenal activity during stress. Neuroscience 1999; 94 (3): 797-802. 
[25] Makino S, Hashimoto K, Gold PW. Multiple feedback mechanisms activating corticotropin-releasing hormone system in the brain during stress. Pharmacol Biochem Behav 2002; 73 (1): 147-58

[26] Marsh DJ, Hollopeter G, Huszar D, et al. Response of melanocortin-4 receptor-deficient mice to anorectic and orexigenic peptides. Nat Genet 1999; 21 (1): 119-22.

[27] Joseph SA, Pilcher WH, Knigge KM. Anatomy of the corticotropin-releasing factor and opiomelanocortin systems of the brain. Fed Proc 1985; 44 (1 Pt 1): 100-7.

[28] Hardwick AJ, Linton EA, Rothwell NJ. Thermogenic effects of the antiglucocorticoid RU-486 in the rat: involvement of corticotropinreleasing factor and sympathetic activation of brown adipose tissue. Endocrinology 1989; 124 (4): 1684-8.

[29] Makino S, Schulkin J, Smith MA, Pacak K, Palkovits M, Gold PW. Regulation of corticotropin-releasing hormone receptor messenger ribonucleic acid in the rat brain and pituitary by glucocorticoids and stress. Endocrinology 1995; 136 (10): 4517-25

[30] Rigter H, Shuster S, Thody AJ. ACTH, alpha-MSH and beta-LPH: pituitary hormones with similar activity in an amnesia test in rats. $\mathbf{J}$ Pharm Pharmacol 1977; 29 (2): 110-1.

[31] Proulx K, Clavel S, Nault G, Richard D, Walker CD. High neonatal leptin exposure enhances brain GR expression and feedback efficacy on the adrenocortical axis of developing rats. Endocrinology 2001; 142 (11): 4607-16.
[32] Meaney MJ, Aitken DH, Bodnoff SR, Iny LJ, Tatarewicz JE, Sapolsky RM. Early postnatal handling alters glucocorticoid receptor concentrations in selected brain regions. Behav Neurosci 1985; 99 (4): 765-70.

[33] Akirav EM, Chan O, Inouye K, Riddell MC, Matthews SG, Vranic M. Partial leptin restoration increases hypothalamic-pituitaryadrenal activity while diminishing weight loss and hyperphagia in streptozotocin diabetic rats. Metabolism 2004; 53(12):1558-64.

[34] Buijs RM, Wortel J, Van Heerikhuize JJ, Kalsbeek A. Novel environment induced inhibition of corticosterone secretion: physiological evidence for a suprachiasmatic nucleus mediated neuronal hypothalamo-adrenal cortex pathway. Brain Res 1997; 758 (1-2): 229-36.

[35] Pralong FP, Roduit R, Waeber G, et al. Leptin inhibits directly glucocorticoid secretion by normal human and rat adrenal gland. Endocrinology 1998; 139 (10): 4264-68.

[36] Rossi J, Balthasar N, Olson D, et al. Melanocortin-4 receptors expressed by cholinergic neurons regulate energy balance and glucose homeostasis. Cell Metab 2011;13(2):195-204.

[37] Nijenhuis WA, Oosterom J, Adan RA. AgRP(83-132) acts as an inverse agonist on the human-melanocortin-4 receptor. Mol Endocrinol 2001; 15(1):164-71.

[38] Tan K, Pogozheva ID, Yeo GSH, et al., Functional characterization and struictural modeling of obesity associated mutations in the melanocortin 4 receptor. Endocrinology 2009; 150(1):114-25.

Received: August 15, 2011

Revised: September 19, 2011

Accepted: September 20, 2011

(C) de Vries et al.; Licensee Bentham Open.

This is an open access article licensed under the terms of the Creative Commons Attribution Non-Commercial License (http://creativecommons.org/licenses/by-nc/3.0/) which permits unrestricted, non-commercial use, distribution and reproduction in any medium, provided the work is properly cited. 